\title{
A NOTE ON HIPPOBOSCA MARTINAGLIA BEDFORD (DIPTERA, HIPPOBOSCIDAE)
}

\author{
By J. BeqUAERT \\ Harvard Medical School and School of Public Health, \\ Boston, Mass.
}

In my second revision of the Hippoboscidæ (1939, Psyche, XLVI, pp. 70-90), I accepted Hippobosca martinaglia Bedford (1939) as a valid species on the basis of the original description and figure. Shortly before his death, the late Dr. G. A. H. Bedford promised to send me a paratype, but unfortunately he was never able to do so. Dr. R. du Toit, Veterinary Research Officer at Onderstepoort, has since gone to considerable trouble in order to clear up the identity of this parasite. It was not possible thus far to trace Bedford's types, which are either mislaid or lost. In July, 1940, Dr. du Toit was, however, able to obtain specimens of a Hippobosca collected on the type host (Impalla, AEpyceros melampus) at the type locality (Bar R Ranch, Swaziland) of $H$. martinaglia. The male and female, which he sent me of this lot, agree well with Bedford's description and they are obviously his species. At the same time it is impossible to separate them from Hippobosca fulva Austen. Bedford's $H$. martinaglia I regard therefore as a synonym of $H$. fulva. The name martinaglia should be removed from the list of valid species of Hippobosca, which now number eight only. In the key of my 1939 paper, couplet 6 should be discarded, the second alternative of couplet 5 running directly to couplet 7 .

The wing of $H$. martinaglia is exactly like that of $H$. fulva, the second longitudinal vein being about as long as the apical section of the third longitudinal (Bedford's figure is incorrect in this respect), and the basal section of the third longitudinal vein is bare. There is only one pair of vertical bristles on the head. The scutellum bears nine preäpical 
bristles in the one female seen and eight in the one male. The arrangement of the tergal sclerotized plates of the abdomen is, in the male, similar to that of the males of $H$. equina and $H$. longipennis, but the first (anterior) two median tergal plates are very small. In the female I can find no trace of a third median tergal plate, the second is small and the first barely indicated (Bedford's figure, drawn from the female, does not show the median tergal plates). The colorpattern, although fairly correctly outlined by Bedford, is by no means as boldly marked as in his figure; it agrees, moreover, with that of other specimens of $H$. fulva seen.

Dr. du Toit also sent me a male of Hippobosca fulva, taken by Mr. Alex. Cuthbertson from a purple-crested lourie or plantain-eater (Gallirex p. porphyrolophus Vigors) on the Sabi River, eastern Transvaal. The host was no doubt accidental.

I may emphasize, on this occasion, that color and markings are, as a rule, without value as specific characters in Hippoboscidae, a fact not fully recognized as yet by some recent authors. Not only do they vary individually within the same species, but they often change in the same specimen. During life, such color changes may be due to age (time elapsed since hatching), to the fed or unfed condition, to parturation (in females), or to the nature of the diet and other environmental factors conditioned by the host. After death, the color of the living insect may be more or less modified by the method of killing and preservation, as well as by the length of time the specimen was kept in collections. 

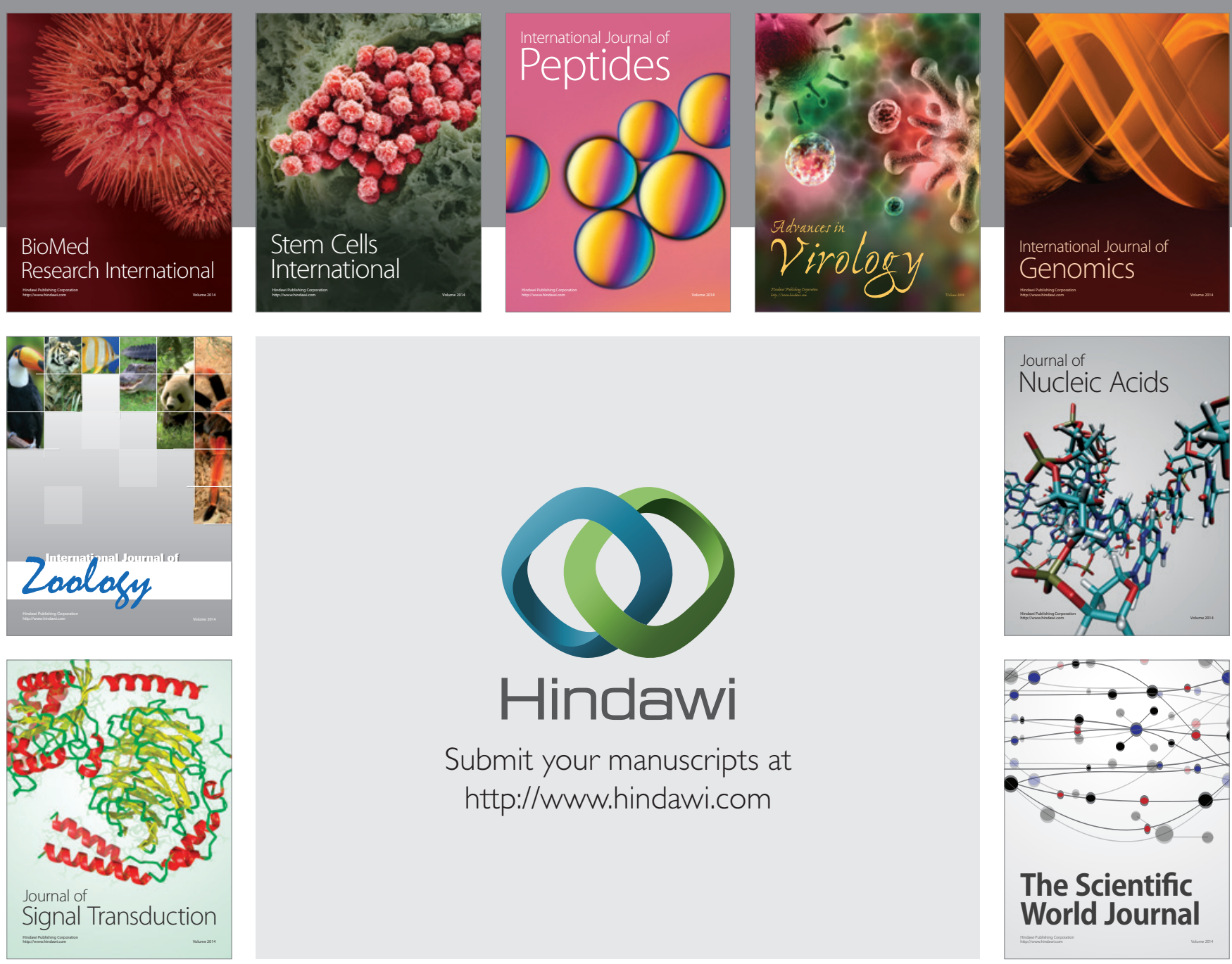

Submit your manuscripts at

http://www.hindawi.com
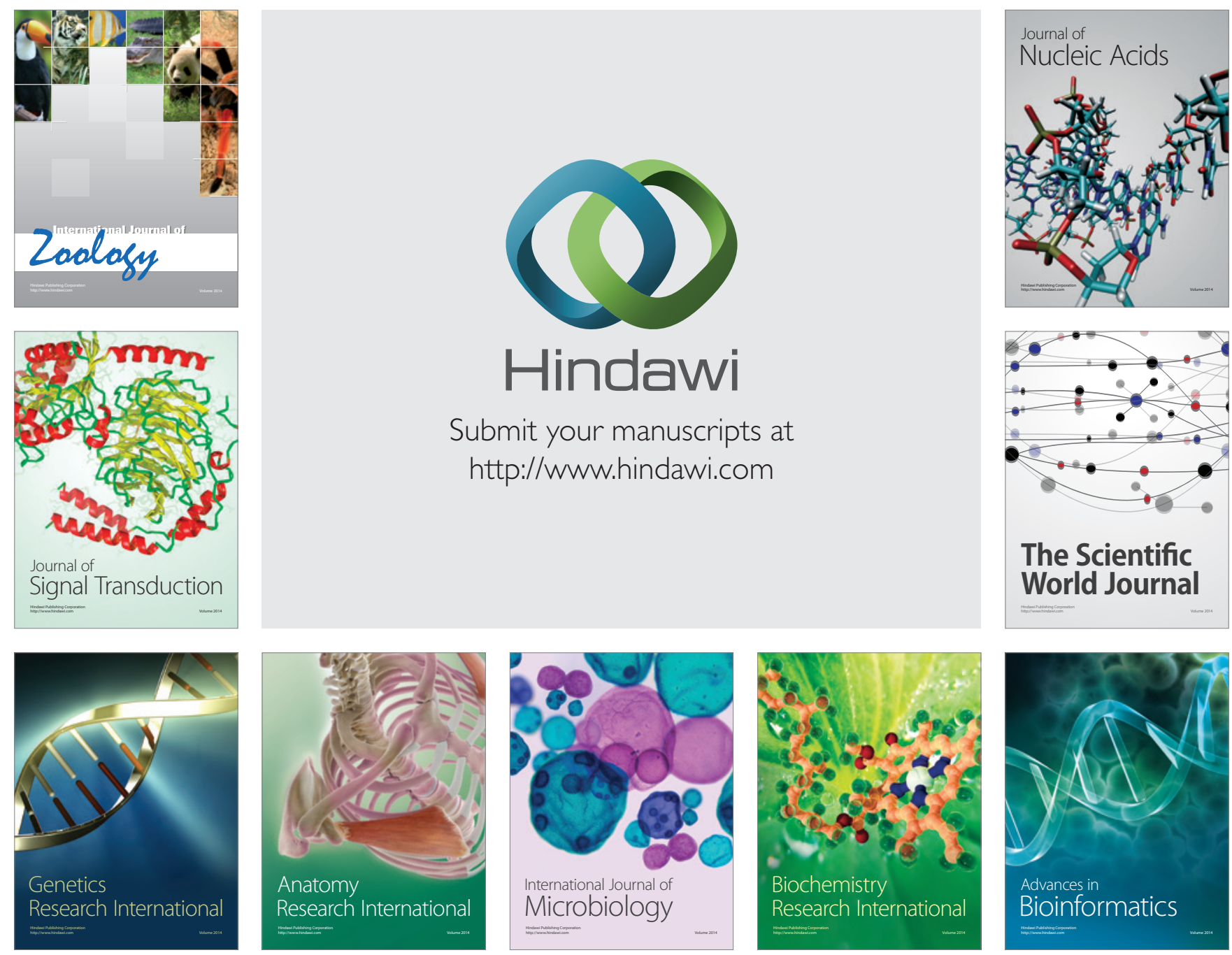

The Scientific World Journal
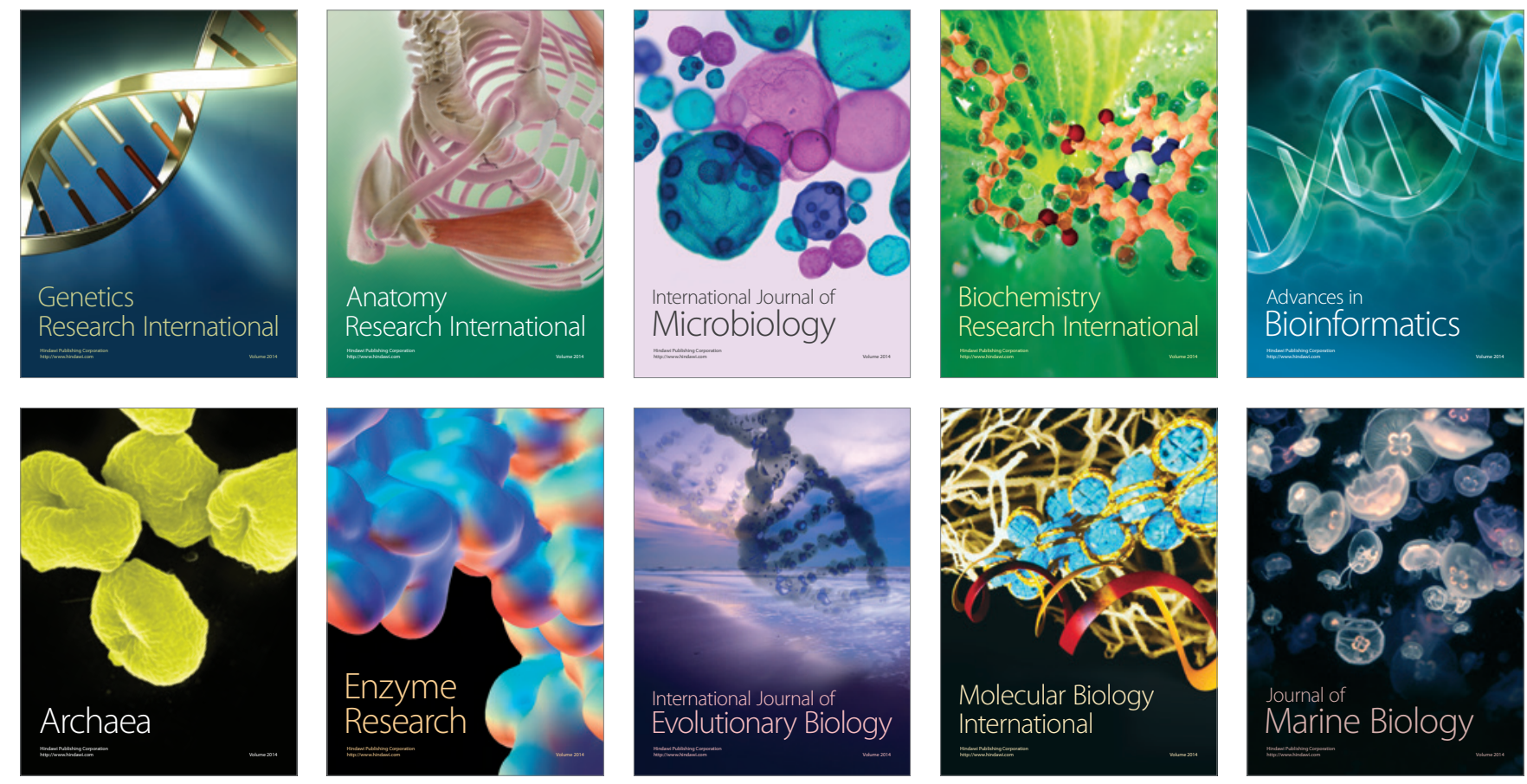